\title{
A Moment Based Approximation for Expected Number of Renewals for Non-Negligible Repair
}

\author{
Dilcu Barnes ${ }^{1, *}$, Saeed Maghsoodloo \\ ${ }^{1}$ Management Science, The University of Alabama in Huntsville, 301 Sparkman Drive, Huntsville, AL 35899, \\ United States of America \\ ${ }^{2}$ ISE Department, Auburn University, Auburn, AL 36849, United States of America
}

Received July 2, 2021; Revised August 24, 2021; Accepted September 21, 2021

\section{Cite This Paper in the following Citation Styles}

(a): [1] Dilcu Barnes, Saeed Maghsoodloo , "A Moment Based Approximation for Expected Number of Renewals for Non-Negligible Repair," Mathematics and Statistics, Vol. 9, No. 5, pp. 773 - 779, 2021. DOI: 10.13189/ms.2021.090516.

(b): Dilcu Barnes, Saeed Maghsoodloo (2021). A Moment Based Approximation for Expected Number of Renewals for Non-Negligible Repair. Mathematics and Statistics, 9(5), 773 - 779. DOI: 10.13189/ms.2021.090516.

Copyright $\odot 2021$ by authors, all rights reserved. Authors agree that this article remains permanently open access under the terms of the Creative Commons Attribution License 4.0 International License

\begin{abstract}
This paper focuses on the renewal function which is simply the mathematical expectation of number of renewals in a stochastic process. Renewal functions are important, and they have various applications in many fields. However, obtaining an analytical expression for the renewal function may be very complicated and even impossible. Therefore, researchers focused on developing approximation methods for them. The purpose of this paper is to explore the renewal functions for non-negligible repair for the most common reliability underlying distributions using the first four raw moments of the failure and repair distributions. This article gives the approximate number of cycles, number of failures and the resulting availability for particular distributions assuming Mean Time to Repair is not negligible and that Time to Restore, or repair has a probability density function denoted as $r(t)$. When Mean Time to Repair is not negligible and Time to Restore has a probability density function denoted as $r(t)$, the expected number of failures, cycles and the resulting availability were obtained by taking the Laplace transforms of corresponding renewal functions. An approximation method for obtaining the expected number of cycles, number of failures and availability using raw moments of failure and repair distributions are provided. Results show that the method produces very accurate results for especially large values of time $t$.
\end{abstract}

Keywords Renewal Function, Availability, Moments, Non-Negligible Repair

\section{Introduction}

Renewal functions give the expected number of failures of a system or a component during a time interval [1]. They have wide variety of applications in decision making such as supply chain planning [2,3], inventory theory [4], continuous sampling plans [5,6], insurance application and sequential analysis $[7,8]$.

Since they have wide variety of applications, obtaining closed form analytical expression for renewal functions have certain advantages including carrying out parametric studies of the functions [9]. However, for most distributions, obtaining the renewal function analytically is complicated and even impossible [2,11]. Therefore, development of computational techniques and approximations for renewal functions has attracted researchers $[10,11]$.

Our previous paper [11] explores the renewal function for minimal repair using time discretizing method. In this paper, we explore the renewal functions for non-negligible repair for commonly used reliability distributions using the first four raw moments of the failure and repair distributions.

Let the variates $X_{1}, X_{2}, X_{3}, \ldots$ represent time to failure $\left(\mathrm{TTF}_{\mathrm{i}}\right)$ be iid (independent and identically distributed) with the underlying failure density $f(\mathrm{x})$ having means $\operatorname{MTBF}$ ( mean time between failures) $=\mu_{x}$ and variance $\sigma_{x}^{2}$; further, let $\mathrm{Y}_{1}, \mathrm{Y}_{2}, \mathrm{Y}_{3}, \ldots$ represent the $\mathrm{i}^{\text {th }}$ Time-to-Repair (TTRi), $+\mathrm{i}=1,2,3,4, \ldots$ with the pdf $r(\mathrm{y})$ having means MTTR $=\mu_{y}$ and variance $\sigma_{y}^{2}$. Then, $\mathrm{T}_{\mathrm{i}}=\mathrm{X}_{\mathrm{i}}$ 
$+\mathrm{Y}_{\mathrm{i}}$ represents the time between cycles (TBCs) which are also iid whose density is given by the convolution $g(t)=f(t) * r(t)$, and whose Laplace transform is given by $\overline{\mathrm{g}}(\mathrm{s})=\overline{\mathrm{f}}(\mathrm{s}) \times \overline{\mathrm{r}}(\mathrm{s})$. Clearly the mean and variance of the cycle-times $\mathrm{T}_{\mathrm{i}}$ 's are $\mu_{x}+\mu_{y}$ and $\sigma_{x}^{2}+\sigma_{y}^{2}$. As described by U. N. Bhat[12] there will be two types of renewals:

(1) A transition from a Y-state (i.e., when system is under repair) to an X-state (at which the system is operating reliably),

(2) A transition from an $X$-state (or operating-reliably-state) to a Y-state (where system will go under repair).

Let $M_{1}(t)$ represent the expected number of renewals of type 1 , and $M_{2}(t)$ represent the expected number of failures (or renewals of type 2). Then, as stated by Bhat[12] and E. A. Elsayed[1], the Laplace transforms of the two renewal functions, respectively, are given by

$$
\begin{gathered}
\overline{\mathrm{M}}_{1}(\mathrm{~s})=\frac{\overline{\mathrm{g}}(\mathrm{s})}{\mathrm{s}[1-\overline{\mathrm{g}}(\mathrm{s})]}=\frac{\overline{\mathrm{f}}(\mathrm{s}) \times \overline{\mathrm{r}}(\mathrm{s})}{\mathrm{s}[1-\overline{\mathrm{f}}(\mathrm{s}) \times \overline{\mathrm{r}}(\mathrm{s})]} \\
\overline{\mathrm{M}}_{2}(\mathrm{~s})=\frac{\overline{\mathrm{f}}(\mathrm{s})}{\mathrm{s}[1-\overline{\mathrm{g}}(\mathrm{s})]}=\frac{\overline{\mathrm{f}}(\mathrm{s})}{\mathrm{s}[1-\overline{\mathrm{f}}(\mathrm{s}) \times \overline{\mathrm{r}}(\mathrm{s})]}
\end{gathered}
$$

General expressions can be obtained for the renewal functions $M_{1}$ and $M_{2}$ by inverting eq. (1a) and eq. (1b). Eq. (1a) shows that

$$
\begin{gathered}
\overline{\mathrm{M}}_{1}(\mathrm{~s})[1-\overline{\mathrm{g}}(\mathrm{s})]=\frac{\overline{\mathrm{g}}(\mathrm{s})}{\mathrm{s}} \rightarrow \overline{\mathrm{M}}_{1}(\mathrm{~s})=\frac{\overline{\mathrm{g}}(\mathrm{s})}{\mathrm{s}}+\overline{\mathrm{M}}_{1}(\mathrm{~s}) \overline{\mathrm{g}}(\mathrm{s}) \\
\rightarrow M_{1}(t)=\mathrm{G}(t)+\int_{0}^{\mathrm{t}} \mathrm{M}_{1}(t-\mathrm{x}) \mathrm{g}(\mathrm{x}) \mathrm{dx},
\end{gathered}
$$

where $G(t)$ is the corresponding cdf of cycle time T.

Eq. (1b) shows that

$$
\begin{gathered}
\overline{\mathrm{M}}_{2}(\mathrm{~s})[1-\overline{\mathrm{g}}(\mathrm{s})]=\frac{\overline{\mathrm{f}}(\mathrm{s})}{\mathrm{s}} \rightarrow \overline{\mathrm{M}}_{2}(\mathrm{~s})=\frac{\overline{\mathrm{f}}(\mathrm{s})}{\mathrm{s}}+\overline{\mathrm{M}}_{2}(\mathrm{~s}) \overline{\mathrm{g}}(\mathrm{s}) \\
\rightarrow M_{2}(t)=\mathrm{F}(t)+\int_{0}^{\mathrm{t}} \mathrm{M}_{2}(t-\mathrm{x}) \mathrm{g}(\mathrm{x}) \mathrm{dx} .
\end{gathered}
$$

Therefore, in general the expected number of type 1 is given by

$$
M_{1}(t)=\mathrm{G}(t)+\int_{0}^{\mathrm{t}} \mathrm{M}_{1}(t-\mathrm{x}) \mathrm{g}(\mathrm{x}) \mathrm{dx} .
$$

while the expected number of failures is

$$
M_{2}(t)=\mathrm{F}(t)+\int_{0}^{\mathrm{t}} \mathrm{M}_{2}(t-\mathrm{x}) \mathrm{g}(\mathrm{x}) \mathrm{dx} .
$$

\section{Exponential TTF and Exponential TTR}

As an example, suppose $\mathrm{TTF}_{\mathrm{i}} \sim \operatorname{Exp}(\lambda)$ and $\mathrm{TTR}_{\mathrm{i}} \sim$ $\operatorname{Exp}(r)$; then as has been documented by numerous other authors [1],

$$
\begin{gathered}
\overline{\mathrm{f}}(\mathrm{s})=\int_{0}^{\infty} \lambda \mathrm{e}^{-\lambda t} \mathrm{e}^{-\mathrm{s} t} d t=\lambda /(\lambda+\mathrm{s}) \text { and } \\
\overline{\mathrm{r}}(\mathrm{s})=\int_{0}^{\infty} \mathrm{re}^{-\mathrm{r} t} \mathrm{e}^{-\mathrm{s} t} d t=\mathrm{r} /(\mathrm{r}+\mathrm{s}) .
\end{gathered}
$$

On substituting these last two Laplace transforms into eq. (1a),

$$
\begin{aligned}
& \overline{\mathrm{M}}_{1}(\mathrm{~s})=\frac{\lambda \mathrm{r}}{\mathrm{s}[(\lambda+\mathrm{s})(\mathrm{r}+\mathrm{s})-\lambda \mathrm{r}]}=\frac{-\lambda \mathrm{r}}{\mathrm{s}^{2}}+\frac{\lambda \mathrm{r}}{\mathrm{s}^{2} \xi}+\frac{\lambda \mathrm{r}}{\xi^{2}(\mathrm{~s}+\xi)}, \\
& \text { where } \xi=\lambda+\mathrm{r} \\
& \mathrm{M}_{1}(\mathrm{t})=L^{-1}\left\{\overline{\mathrm{M}}_{1}(\mathrm{~s})\right\}=L^{-1}\left\{\frac{-\lambda \mathrm{r}}{\mathrm{s} \xi^{2}}+\frac{\lambda \mathrm{r}}{\mathrm{s}^{2} \xi}+\frac{\lambda \mathrm{r}}{\xi^{2}(\mathrm{~s}+\xi)}\right\}=\frac{-\lambda \mathrm{r}}{\xi^{2}}+\frac{\lambda \mathrm{r}}{\xi} t+\frac{\lambda \mathrm{r}}{\xi^{2}} \mathrm{e}^{-\xi t}
\end{aligned}
$$

which gives the expected number of transitions from a repair-state to an operational-state. Similarly,

$$
\overline{\mathrm{M}}_{2}(\mathrm{~s})=\frac{\overline{\mathrm{f}}(\mathrm{s})}{\mathrm{s}[1-\overline{\mathrm{f}}(\mathrm{s}) \times \overline{\mathrm{r}}(\mathrm{s})]}=\frac{\lambda^{2}}{\mathrm{~s} \xi^{2}}+\frac{\lambda \mathrm{r}}{\mathrm{s}^{2} \xi}-\frac{\lambda^{2}}{\xi^{2}(\mathrm{~s}+\xi)},
$$

which upon inversion yields

$$
M_{2}(t)=\frac{\lambda^{2}}{\xi^{2}}+\frac{\lambda \mathrm{r}}{\xi} t-\frac{\lambda^{2}}{\xi^{2}} \mathrm{e}^{-\xi t},
$$

representing the expected number of failures during an interval of length $t$.

Note that the limit of both renewal functions $M_{1}(t)$ and $M_{2}(t)$ as $r \rightarrow \infty$ is equal to $\lambda t$ as expected. Further, a comparison of $M_{2}(t)$ with $M_{1}(t)$ reveals that $M_{2}(t)>M_{1}(t)$ for all $t>0$, which is intuitively meaningful because the expected number of failures must exceed the expected number of cycles for all $t>0$. As an example, if $\lambda=$ $0.0005 /$ hour and repair-rate $r=0.05$, then $M_{1}(t=$ $1000)=0.4852465 \quad, \quad$ while $\quad M_{2}(t=1000)=$ 0.4951475 .

\section{System Availability}

Availability is the probability that a system or component is performing its required function at a given point in time or over a stated period of time when operated and maintained in a prescribed manner [13].

Because we are assuming that a system can be either in an operational-state, or under repair, then the reliability function must be replaced by the instantaneous (or point) availability function at time $t$, denoted $A(t)$, which represents the probability that a repairable unit or system is 
functioning reliably at time $t$. Thus, if there is no repair, the availability function is simply $A(t)=R(t)$, the reliability function. However, if a component (or system) is repairable, then there are two mutually exclusive possibilities:

(1) The system is reliable at $t$, in which case $A_{1}(t)=R(t)$,

(2) The system fails at time $\mathrm{x}, 0<\mathrm{x}<t$, gets renewed (or restored to almost as-good-as-new) in the interval ( $\mathrm{x}$, $\mathrm{x}+\Delta \mathrm{x})$ with probability element $\rho(\mathrm{x}) \mathrm{dx}$, and then is reliable from time $\mathrm{x}$ to time $t$ [14].

This second availability is given by $A_{2}(t)=\int_{0}^{t} \rho(\mathrm{x}) \mathrm{dx} R(t-\mathrm{x})$. Because the above two cases are mutually exclusive, then

$$
A(t)=A_{1}(t)+A_{2}(t)=R(t)+\int_{0}^{t} R(t-\mathrm{x}) \rho(\mathrm{x}) \mathrm{dx} .
$$

Taking Laplace transform of eq. (3) [and observing that the integral is the convolution of $R(t)$ with $\rho(\mathrm{t})]$ yields

$$
\begin{aligned}
& \overline{\mathrm{A}}(\mathrm{s})=\overline{\mathrm{R}}(\mathrm{s})+\overline{\mathrm{R}}(\mathrm{s}) \bar{\rho}(\mathrm{s})=\overline{\mathrm{R}}(\mathrm{s})[1+\bar{\rho}(\mathrm{s})]= \\
& =\overline{\mathrm{R}}(\mathrm{s})\left[1+\frac{\overline{\mathrm{f}}(\mathrm{s}) \times \overline{\mathrm{r}}(\mathrm{s})}{1-\overline{\mathrm{f}}(\mathrm{s}) \times \overline{\mathrm{r}}(\mathrm{s})}\right]=\frac{\overline{\mathrm{R}}(\mathrm{s})}{1-\overline{\mathrm{f}}(\mathrm{s}) \times \overline{\mathrm{r}}(\mathrm{s})}
\end{aligned}
$$

where $r(t)$ is the density of repair-time.

The inverse Laplace transform of Eq. (4) results in the point availability $A(t)$. If the underlying distributions are not exponential, problems arise in inverting the Laplace transform [15]. Therefore, numerical solutions and approximations become the only alternatives for obtaining $A(t)$ [16]. There are numerous approximation techniques in the literature such as, Sarkar \& Chaudhuri [15] uses Fourier transform technique to determine the availability of a maintained system under continuous monitoring and with perfect repair policy. They also obtain closed-form expressions when the system has gamma life distribution and exponential repair time. Ananda and Gamage[17] consider statistical inference for the steady state availability of a system when repair distribution is two-parameter lognormal and failure distributions are Weibull, gamma and lognormal. There are also other articles in the literature that work on confidence limits for steady state availability of a system such as $[18,19]$ etc.

In order to approximate availability and renewal functions we used moment-based approximation, which only requires knowing the first four raw moments of failure and repair distributions. "There are a number of cases where the moments of a distribution are easily obtained, but theoretical distributions are not available in closed form [20]." And also, efficient estimators for the various moments of the underlying distribution could be calculated from the observed sample data [21]. Kambo et. al. [21], uses first three moments of failure distribution in order to approximate the renewal function for negligible repair and they conclude that the method produces exact results of the renewal function for certain important distributions like mixture of two exponential and Coxian-2.

In this paper, we propose an approximation for the evaluation of expected number of cycles, number of failures and availability based on first four raw moments of failure and repair distributions where convolution of $f(t)$ and $r(t)$ is intractable. We conclude that the method produces very accurate results for especially large values of time $t$.

\section{Intractable Convolutions of $F(T)$ with $R(T)$}

Obtaining the convolutions of $f(t)$ with $r(t)$ for the general classes of failure and repair distributions is not always tractable, such is the case of both TTF and TTR being Weibull, then $g(t)$ cannot be obtained. Therefore, below we will develop an approximate method based on raw moments that will yield approximations for the three functions $M_{1}(t), M_{2}(t)$, and the resulting $A(t)$ for any failure and repair distributions.

It has been well documented, since Pierre Laplace, that the Laplace transform of any density function is given by $\overline{\mathrm{f}}(\mathrm{s})=\int_{0}^{\infty} \mathrm{e}^{-\mathrm{st}} f(\mathrm{t}) \mathrm{dt}$, where the dummy-variable s must exceed zero. Such a Laplace-transformation is quite often necessary because the solution in the s-space is much easier to obtain than the direct solution from the t-space. As discussed in the introduction, $\overline{\mathrm{M}}_{1}(\mathrm{~s})=\frac{\overline{\mathrm{f}}(\mathrm{s}) \times \overline{\mathrm{r}}(\mathrm{s})}{\mathrm{s}[1-\overline{\mathrm{f}}(\mathrm{s}) \times \overline{\mathrm{r}}(\mathrm{s})]}$, and $\overline{\mathrm{M}}_{2}(\mathrm{~s})=\frac{\overline{\mathrm{f}}(\mathrm{s})}{\mathrm{s}[1-\overline{\mathrm{f}}(\mathrm{s}) \times \overline{\mathrm{r}}(\mathrm{s})]}$. So that these last 2 Laplace transforms have identical denominators and is given by $\mathrm{D}(\mathrm{s})=\mathrm{s}[1-\overline{\mathrm{f}}(\mathrm{s}) \times \overline{\mathrm{r}}(\mathrm{s})]$; this will aid in obtaining approximations for $M_{1}(t)$ and $M_{2}(t)$, and the resulting $A(t) \cong 1+M_{1}(t)-M_{2}(t)$.

$$
\overline{\mathrm{f}}(\mathrm{s})=\int_{0}^{\infty} \mathrm{e}^{-\mathrm{st}} f(\mathrm{t}) \mathrm{dt}=\int_{0}^{\infty}\left(1-\mathrm{st}+\mathrm{s}^{2} \mathrm{t}^{2} / 2 !-\mathrm{s}^{3} \mathrm{t}^{3} / 3 !+\mathrm{s}^{4} \mathrm{t}^{4} / 4 !-\ldots\right) \mathrm{f}(\mathrm{t}) \mathrm{dt}
$$

where we have made use of the Maclaurin series for $e^{-s t}$. Using the definition of statistical raw moments, eq. (5a) yields

$$
\overline{\mathrm{f}}(\mathrm{s})=\int_{0}^{\infty} \mathrm{e}^{-\mathrm{st}} f(\mathrm{t}) \mathrm{dt}=1-\mu_{1}^{\prime} \mathrm{s}+\mu_{2}^{\prime} \mathrm{s}^{2} / 2 !-\mu_{3}^{\prime} \mathrm{s}^{3} / 3 !+\mu_{4}^{\prime} \mathrm{s}^{4} / 4 !-\ldots .
$$

where $\quad \mu_{k}^{\prime}=\int_{0}^{\infty} t^{k} f(t) d t$. Similarly, for the repair-density, $r(t)$, we have its 
Laplace transform as:

$$
\overline{\mathrm{r}}(\mathrm{s})=1-\mathrm{m}_{1} \mathrm{~s}+\mathrm{m}_{2} \mathrm{~s}^{2} / 2 !-\mathrm{m}_{3} \mathrm{~s}^{3} / 3 !+\mathrm{m}_{4} \mathrm{~s}^{4} / 4 !-\ldots
$$

where $\mathrm{m}_{\mathrm{k}}=\int_{0}^{\infty} \mathrm{t}^{\mathrm{k}} r(\mathrm{t}) \mathrm{dt}$ is the $\mathrm{k}^{\text {th }}$ raw moment of TTR. Therefore, in terms of raw moments the denominators of $\mathrm{M}_{1}(\mathrm{~s})$ and $\mathrm{M}_{2}$ (s) are given by

$$
\begin{aligned}
& D(s)=s\left[\begin{array}{r}
1-\left(1-\mu_{1}^{\prime} s+\mu_{2}^{\prime} s^{2} / 2 !-\mu_{3}^{\prime} s^{3} / 3 !+\mu_{4}^{\prime} s^{4} / 4 !-\ldots .\right) \times \\
\left(1-m_{1} s+m_{2} s^{2} / 2 !-m_{3} s^{3} / 3 !+m_{4} s^{4} / 4 !-\ldots\right)
\end{array}\right] \\
& =s\left[\begin{array}{l}
\left(\mu_{1}^{\prime}+m_{1}\right) s-\left(\mu_{2}^{\prime}+m_{2}+2 \mu_{1}^{\prime} m_{1}\right)\left(s^{2} / 2\right) \\
+\left(\mu_{3}^{\prime}+m_{3}+3 \mu_{1}^{\prime} m_{2}+3 \mu_{2}^{\prime} m_{1}\right)\left(s^{3} / 6\right) \\
-\left(\mu_{4}^{\prime}+m_{4}+4 \mu_{3}^{\prime} m_{1}+6 \mu_{2}^{\prime} m_{2}+4 \mu_{1}^{\prime} m_{3}\right)\left(s^{4} / 24\right) \\
+\left(\mu_{4}^{\prime} m_{1}+2 \mu_{3}^{\prime} m_{2}+2 \mu_{2}^{\prime} m_{3}+\mu_{1}^{\prime} m_{4}\right)\left(s^{5} / 24\right) \\
-\left(3 \mu_{4}^{\prime} m_{2}+4 \mu_{3}^{\prime} m_{3}+3 \mu_{2}^{\prime} m_{4}\right)\left(s^{6} / 144\right) \\
+\left(\mu_{3}^{\prime} m_{4}+\mu_{4}^{\prime} m_{3}\right)\left(s^{7} / 144\right)-\mu_{4}^{\prime} m_{4}\left(s^{8} / 576\right)+\ldots
\end{array}\right] \\
& =s^{2}\left[\begin{array}{l}
\left(\mu_{1}^{\prime}+m_{1}\right)-\left(\mu_{2}^{\prime}+m_{2}+2 \mu_{1}^{\prime} m_{1}\right)(s / 2) \\
+\left(\mu_{3}^{\prime}+m_{3}+3 \mu_{1}^{\prime} m_{2}+3 \mu_{2}^{\prime} m_{1}\right)\left(s^{2} / 6\right) \\
-\left(\mu_{4}^{\prime}+m_{4}+4 \mu_{3}^{\prime} m_{1}+4 \mu_{1}^{\prime} m_{3}+6 \mu_{2}^{\prime} m_{2}\right)\left(s^{3} / 24\right) \\
+\left(\mu_{4}^{\prime} m_{1}+2 \mu_{3}^{\prime} m_{2}+2 \mu_{2}^{\prime} m_{3}+\mu_{1}^{\prime} m_{4}\right)\left(s^{4} / 24\right) \\
-\left(3 \mu_{4}^{\prime} m_{2}+4 \mu_{3}^{\prime} m_{3}+3 \mu_{2}^{\prime} m_{4}\right)\left(s^{5} / 144\right) \\
+\left(\mu_{3}^{\prime} m_{4}+\mu_{4}^{\prime} m_{3}\right)\left(s^{6} / 144\right)-\left(\mu_{4}^{\prime} m_{4}\right)\left(s^{7} / 576\right)+\ldots
\end{array}\right]
\end{aligned}
$$

Note that the inclusion of higher exponents $s^{8}, s^{9}$, etc. in the brackets inside eq. (6a) will require the $5^{\text {th }}, 6^{\text {th }}$, etc. raw moments in the above $\mathrm{D}(\mathrm{s})$ which we will not consider. Thus, the $4^{\text {th }}$-order approximation for $\mathrm{D}(\mathrm{s})$ is given by

$$
\mathrm{D}(\mathrm{s}) \approx \mathrm{s}^{2}\left[\begin{array}{l}
\left(\mu_{1}^{\prime}+\mathrm{m}_{1}\right)-\left(\mu_{2}^{\prime}+\mathrm{m}_{2}+2 \mu_{1}^{\prime} \mathrm{m}_{1}\right)(\mathrm{s} / 2) \\
+\left(\mu_{3}^{\prime}+\mathrm{m}_{3}+3 \mu_{1}^{\prime} \mathrm{m}_{2}+3 \mu_{2}^{\prime} \mathrm{m}_{1}\right)\left(\mathrm{s}^{2} / 6\right) \\
-\left(\mu_{4}^{\prime}+\mathrm{m}_{4}+4 \mu_{3}^{\prime} \mathrm{m}_{1}+4 \mu_{1}^{\prime} \mathrm{m}_{3}+6 \mu_{2}^{\prime} \mathrm{m}_{2}\right)\left(\mathrm{s}^{3} / 24\right) \\
+\left(\mu_{4}^{\prime} \mathrm{m}_{1}+2 \mu_{3}^{\prime} \mathrm{m}_{2}+2 \mu_{2}^{\prime} \mathrm{m}_{3}+\mu_{1}^{\prime} \mathrm{m}_{4}\right)\left(\mathrm{s}^{4} / 24\right) \\
-\left(3 \mu_{4}^{\prime} \mathrm{m}_{2}+4 \mu_{3}^{\prime} \mathrm{m}_{3}+3 \mu_{2}^{\prime} \mathrm{m}_{4}\right)\left(\mathrm{s}^{5} / 144\right) \\
+\left(\mu_{3}^{\prime} \mathrm{m}_{4}+\mu_{4}^{\prime} \mathrm{m}_{3}\right)\left(\mathrm{s}^{6} / 144\right)-\left(\mu_{4}^{\prime} \mathrm{m}_{4}\right)\left(\mathrm{s}^{7} / 576\right)
\end{array}\right]
$$

Before setting up partial fractions for $\overline{\mathrm{M}}_{1}(\mathrm{~s})=\frac{\overline{\mathrm{f}}(\mathrm{s}) \times \overline{\mathrm{r}}(\mathrm{s})}{\mathrm{s}[1-\overline{\mathrm{f}}(\mathrm{s}) \times \overline{\mathrm{r}}(\mathrm{s})]}$, it will be judicious to first multiply the numerator and denominator by 576 and then divide both by $b_{7}=-\mu_{4}^{\prime} \mathrm{m}_{4}$ so that $\overline{\mathrm{M}}_{1}(\mathrm{~s})$ will take the following form:

$$
\begin{aligned}
& \overline{\mathrm{M}}_{1}(\mathrm{~s})= \\
& \frac{576\left[\left(1-\mu_{1}^{\prime} \mathrm{s}+\mu_{2}^{\prime} \mathrm{s}^{2} / 2 !-\mu_{3}^{\prime} \mathrm{s}^{3} / 3 !+\mu_{4}^{\prime} \mathrm{s}^{4} / 4 !\right) \times\left(1-\mathrm{m}_{1} \mathrm{~s}+\mathrm{m}_{2} \mathrm{~s}^{2} / 2 !-\mathrm{m}_{3} \mathrm{~s}^{3} / 3 !+\mathrm{m}_{4} \mathrm{~s}^{4} / 4 !\right) / \mathrm{b}_{7}\right]}{\mathrm{s}^{2}\left[\mathrm{~s}^{7}+\mathrm{b}_{6} \mathrm{~s}^{6}+\mathrm{b}_{5} \mathrm{~s}^{5}+\mathrm{b}_{4} \mathrm{~s}^{4}+\mathrm{b}_{3} \mathrm{~s}^{3}+\mathrm{b}_{2} \mathrm{~s}^{2}+\mathrm{b}_{1} \mathrm{~s}+\mathrm{b}_{0}\right]} \\
& \mathrm{b}_{6}=4\left(\mu_{3}^{\prime} \mathrm{m}_{4}+\mu_{4}^{\prime} \mathrm{m}_{3}\right) / \mathrm{b}_{7} \\
& \mathrm{~b}_{5}=-4\left(3 \mu_{4}^{\prime} \mathrm{m}_{2}+4 \mu_{3}^{\prime} \mathrm{m}_{3}+3 \mu_{2}^{\prime} \mathrm{m}_{4}\right) / \mathrm{b}_{7} \\
& \mathrm{~b}_{4}=24\left(\mu_{4}^{\prime} \mathrm{m}_{1}+2 \mu_{3}^{\prime} \mathrm{m}_{2}+2 \mu_{2}^{\prime} \mathrm{m}_{3}+\mu_{1}^{\prime} \mathrm{m}_{4}\right) / \mathrm{b}_{7} \\
& \mathrm{~b}_{3}=-24\left(\mu_{4}^{\prime}+\mathrm{m}_{4}+4 \mu_{3}^{\prime} \mathrm{m}_{1}+4 \mu_{1}^{\prime} \mathrm{m}_{3}+6 \mu_{2}^{\prime} \mathrm{m}_{2}\right) / \mathrm{b}_{7} \\
& \mathrm{~b}_{2}=96\left(\mu_{3}^{\prime}+\mathrm{m}_{3}+3 \mu_{1}^{\prime} \mathrm{m}_{2}+3 \mu_{2}^{\prime} \mathrm{m}_{1}\right) / \mathrm{b}_{7} \\
& \mathrm{~b}_{1}=-288\left(\mu_{2}^{\prime}+\mathrm{m}_{2}+2 \mu_{1}^{\prime} \mathrm{m}_{1}\right) / \mathrm{b}_{7} \\
& \mathrm{~b}_{0}=576\left(\mu_{1}^{\prime}+\mathrm{m}_{1}\right) / \mathrm{b}_{7}
\end{aligned}
$$


The above $\overline{\mathrm{M}}_{1}$ (s) can now be partial fractionated as follows:

$$
\begin{aligned}
& \bar{M}_{1}(s)=\frac{c_{1}}{s}+\frac{c_{2}}{s^{2}}+\frac{c_{3}}{s-r_{3}}+\frac{c_{4}}{s-r_{4}}+\frac{c_{5}}{s-r_{5}}+ \\
& +\frac{c_{6}}{s-r_{6}}+\frac{c_{7}}{s-r_{7}}+\frac{c_{8}}{s-r_{8}}+\frac{c_{9}}{s-r_{9}}
\end{aligned}
$$

where ri, $\mathrm{i}=3,4,5,6,7,8$ and 9 are the seven real and complex-conjugate pairs of roots of the polynomial $\mathrm{P}_{7}=\mathrm{s}^{7}+\mathrm{b}_{6} \mathrm{~s}^{6}+\mathrm{b}_{5} \mathrm{~s}^{5}+\mathrm{b}_{4} \mathrm{~s}^{4}+\mathrm{b}_{3} \mathrm{~s}^{3}+\mathrm{b}_{2} \mathrm{~s}^{2}+\mathrm{b}_{1} \mathrm{~s}+\mathrm{b}_{0} \quad$. A comparison of eq. (7b) with (7a) shows that $c_{2}=-576 /\left(R_{7} b_{7}\right)$, where $R_{7}=\prod_{i=3}^{9} r_{i}$ is the product of all the seven roots and will be real-valued.

Similarly, $c_{1}=c_{2} \times R_{6} / R_{7}+576\left(\mu_{1}^{\prime}+m_{1}\right) /\left(b_{7} R_{7}\right)$, where $\mathrm{R}_{6}=\sum \prod_{\mathrm{i}=3} \mathrm{r}_{\mathrm{i}}$ is the sum of products of any distinct six roots out of seven. Once the seven roots are obtained, then the values of $c_{1}$ and $c_{2}$ can be computed, and a good approximation of $M_{1}(t)$ is given by $M_{1}(t) \cong \mathrm{c}_{1}+\mathrm{c}_{2} t$. In order to solve the partial-fraction coefficients $c_{3}, c_{4}, \ldots, c_{9}$, we must obtain seven equations in seven unknowns by comparing (7b) with (7a) such that the expression for $\overline{\mathrm{M}}_{1}(\mathrm{~s})$ in eq. (7b) will exactly equal to the one in eq. (7a). The coefficient for $c_{3}$ will be obtained by equation the coefficient of $s^{2}$ in the numerator of (7b) with that of (7a). This yields the first equation in seven unknowns, as shown below:

$$
\begin{aligned}
& c_{1} R_{6}-c_{2} R_{5}+c_{3} \prod_{i \neq 3}^{9} r_{i}+c_{4} \prod_{i \neq 4}^{9} r_{i}+c_{5} \prod_{i \neq 5}^{9} r_{i}+c_{6} \prod_{i \neq 6}^{9} r_{i}+c_{7} \prod_{i \neq 7}^{9} r_{i}+c_{8} \prod_{i \neq 8}^{9} r_{i}+c_{9} \prod_{i=3}^{8} r_{i} \\
& =576\left(\mathrm{~m}_{2} / 2+\mu_{1}^{\prime} \mathrm{m}_{1}+\mu_{2}^{\prime} / 2\right) / \mathrm{b}_{7} \text {, }
\end{aligned}
$$

where $R_{5}=\sum \prod_{i=3} r_{i}$ is the sum of products of any 5 distinct roots.

Thus the first equation is,

$$
\begin{aligned}
& \mathrm{c}_{3} \prod_{\mathrm{i} \neq 3}^{9} \mathrm{r}_{\mathrm{i}}+\mathrm{c}_{4} \prod_{\mathrm{i} \neq 4}^{9} \mathrm{r}_{\mathrm{i}}+\mathrm{c}_{5} \prod_{\mathrm{i} \neq 5}^{9} \mathrm{r}_{\mathrm{i}}+\mathrm{c}_{6} \prod_{\mathrm{i} \neq 6}^{9} \mathrm{r}_{\mathrm{i}}+\mathrm{c}_{7} \prod_{i \neq 7}^{9} \mathrm{r}_{\mathrm{i}}+\mathrm{c}_{8} \prod_{\mathrm{i} \neq 8}^{9} \mathrm{r}_{\mathrm{i}}+\mathrm{c}_{9} \prod_{\mathrm{i}=3}^{8} \mathrm{r}_{\mathrm{i}} \\
& =288\left(\mathrm{~m}_{2}+2 \mu_{1}^{\prime} \mathrm{m}_{1}+\mu_{2}^{\prime}\right) / \mathrm{b} 7+\mathrm{c}_{2} \mathrm{R}_{5}-\mathrm{c}_{1} \mathrm{R}_{6}
\end{aligned}
$$

The comparison of $s^{3}$ coefficients will give rise to the second equation in the seven unknowns $c_{3}, c_{4}, \ldots, c_{9}$. Letting $R_{j 5}=\sum \prod_{i \neq j} r_{i}, j=3,4 \ldots 9$ be the sum of products of any five distinct roots out of seven, excluding the $\mathrm{j}^{\text {th }}$ root, and hence it will have exactly ${ }_{6} \mathrm{C}_{5}=6$ terms. Using these notations, the second equation by comparing the coefficients of $\mathrm{s}^{3}$ will be as follows:

$$
\begin{aligned}
& c_{3} R_{35}+c_{4} R_{45}+c_{5} R_{55}+c_{6} R_{65}+c_{7} R_{75}+c_{8} R_{85}+c_{9} R_{95} \\
& =-c_{1} R_{5}+c_{2} R_{4}+96\left(m_{3}+3 \mu_{1}^{\prime} m_{2}+3 \mu_{2}^{\prime} m_{1}+\mu_{3}^{\prime}\right) / b_{7},
\end{aligned}
$$

where $\mathrm{R}_{4}=\sum \prod_{\mathrm{i}=3} \mathrm{r}_{\mathrm{i}}$ has ${ }_{7} \mathrm{C}_{4}=35$ terms of products of any distinct four out of seven roots.

Similarly, letting $R_{j 4}=\sum \prod_{i \neq j} r_{i}, j=3,4, \ldots, 9$ be the sum of products of any four distinct roots out of seven excluding the $\mathrm{j}^{\text {th }}$ roots and equating the coefficients of $\mathrm{s}^{4}$, we obtain the third equation

$$
\begin{aligned}
& c_{3} R_{34}+c_{4} R_{44}+c_{5} R_{54}+c_{6} R_{64}+c_{7} R_{74}+c_{8} R_{84}+c_{9} R_{94} \\
& =-c_{1} R_{4}+c_{2} R_{3}+24\left(m_{4}+4 \mu_{1}^{\prime} m_{3}+6 \mu_{2}^{\prime} m_{2}+4 \mu_{3}^{\prime} m_{1}+\mu_{4}^{\prime}\right) / b_{7},
\end{aligned}
$$

where $R_{3}=\sum \prod_{i=3} r_{i}$ is the sum of products of any three distinct roots out of seven. Note that in the definition of $\mathrm{Rji}$, the second index $\mathrm{i}$ always indicates the number of roots in the product $\prod r_{i}$. Next equating the coefficients of $\mathrm{s} 5$ results in

$$
\begin{aligned}
& c_{3} R_{33}+c_{4} R_{43}+c_{5} R_{53}+c_{6} R_{63}+c_{7} R_{73}+c_{8} R_{83}+c_{9} R_{93} \\
& =-c_{1} R_{3}+c_{2} R_{2}+24\left(\mu_{1}^{\prime} m_{4}+2 \mu_{2}^{\prime} m_{3}+2 \mu_{3}^{\prime} m_{2}+\mu_{4}^{\prime} m_{1}\right) / b_{7}
\end{aligned}
$$

Next equating the coefficients of $s^{6}$ results in:

$$
\begin{aligned}
& c_{3} R_{32}+c_{4} R_{42}+c_{5} R_{52}+c_{6} R_{62}+c_{7} R_{72}+c_{8} R_{82}+c_{9} R_{92} \\
& =-c_{1} R_{2}+c_{2} R_{1}+4\left(3 \mu_{2}^{\prime} m_{4}+4 \mu_{3}^{\prime} m_{3}+3 \mu_{4}^{\prime} m_{2}\right) / b_{7},
\end{aligned}
$$

where $R_{1}=\sum_{i=3}^{9} r_{i}$ is the sum of all seven roots. Equating the coefficients of $s^{7}$ results in:

$$
\begin{aligned}
& c_{3} R_{31}+c_{4} R_{41}+c_{5} R_{51}+c_{6} R_{61}+c_{7} R_{71}+c_{8} R_{81}+c_{9} R_{91} \\
& =-c_{1} R_{1}+c_{2}+4\left(\mu_{3}^{\prime} m_{4}+\mu_{4}^{\prime} m_{3}\right) / b_{7},
\end{aligned}
$$

where $R_{j 1}=\sum_{i \neq j}^{9} r_{i}$. Finally, equating the coefficients of $s^{8}$ will yield the last equation.

$\mathrm{c}_{3}+\mathrm{c}_{4}+\mathrm{c}_{5}+\mathrm{c}_{6}+\mathrm{c}_{7}+\mathrm{c}_{8}+\mathrm{c}_{9}=-\mathrm{c}_{1}+\mu_{4}^{\prime} \mathrm{m}_{4} / \mathrm{b}_{7}=-\mathrm{c}_{1}-1$ We now use the equation $\overline{\mathrm{M}}_{2}(\mathrm{~s})=\frac{\overline{\mathrm{f}}(\mathrm{s})}{\mathrm{s}[1-\overline{\mathrm{f}}(\mathrm{s}) \times \overline{\mathrm{r}}(\mathrm{s})]}$ in order to obtain the $4^{\text {th }}$-order approximation for $M_{2}(t)$. Because $\bar{M}_{2}(\mathrm{~s})$ has the same denominator as $\overline{\mathrm{M}}_{1}(\mathrm{~s})$, then

$$
\bar{M}_{2}(s)=\frac{576\left(1-\mu_{1}^{\prime} s+\mu_{2}^{\prime} s^{2} / 2 !-\mu_{3}^{\prime} s^{3} / 3 !+\mu_{4}^{\prime} s^{4} / 4 !\right) / b_{7}}{s^{2}\left(s^{7}+b_{6} s^{6}+b_{5} s^{5}+b_{4} s^{4}+b_{3} s^{3}+b_{2} s^{2}+b_{1} s+b_{0}\right)}
$$

where the seven denominator roots $r_{3}, \ldots, r_{9}$ will be the same as those of $\bar{M}_{1}(\mathrm{~s})$. On a comparison of eq. (8) with eq. (7b) will show that $c_{2}=-576 /\left(R_{7} b_{7}\right)$ will stay intact, but $c_{1}=c_{2} \times R_{6} / R_{7}+576 \mu_{1}^{\prime} /\left(b_{7} R_{7}\right)$. The seven equations in seven unknowns can easily be obtained from the seven equations for $\overline{\mathrm{M}}_{1}(\mathrm{~s})$ and replacing $\mathrm{m}_{1}, \mathrm{~m}_{2}, \mathrm{~m}_{3}$, and $\mathrm{m}_{4}$ therein by zeros in every term. Once $M_{2}(t)$ is approximated, then $A(t) \approx 1+M_{1}(t)-M_{2}(t)$. 


\section{Summary and Conclusions}

The moment-based approximation for expected number of cycles $M_{1}(t)$, number of failures $M_{2}(t)$ and availability $A(t)$ were obtained for the three parameter Weibull, normal, lognormal, exponential, logistic, loglogistic and gamma distribution as failure and repair distributions. As we discussed in Section 2, the exact results of $M_{1}(t), M_{2}(t)$ and $A(t)$ when TTF and TTR are exponentially distributed have been known. So, we used those results at $\lambda=0.001$ and $r=$ 0.05 to compare the approximation method that we have developed. Based on these results relative errors were calculated and concluded that the method produces very accurate results for especially large values of $t$ versus small values of $t$. The figures and tables below explain the results better.

Table 1 shows the error of approximation relative to the exact value. As it is seen from the table relative error is almost $95 \%$ when time is 20 units, but as the time increases relative error decreases dramatically. Moreover, when time is 5000 units and relative error is zero on the six decimals.

Table 1. Moment Based Approximation Results for $M_{1}(t)$

\begin{tabular}{|c|c|c|c|}
\hline Time & Exact Values & $\begin{array}{c}\text { Approximation } \\
\text { Results }\end{array}$ & Rel-Err \\
\hline 20 & 0.007316319 & 0.0003845 & $-94.745069 \%$ \\
\hline 50 & 0.031297225 & 0.0297962 & $-4.795931 \%$ \\
\hline 100 & 0.07893304 & 0.0788158 & $-0.148480 \%$ \\
\hline 250 & 0.225874719 & 0.2258747 & $-0.000026 \%$ \\
\hline 500 & 0.470972703 & 0.4709727 & $-0.000001 \%$ \\
\hline 1000 & 0.961168781 & 0.9611688 & $0.000000 \%$ \\
\hline 2000 & 1.941560938 & 1.9415609 & $-0.000002 \%$ \\
\hline 5000 & 4.882737409 & 4.8827374 & $0.000000 \%$ \\
\hline
\end{tabular}

Table 2 shows the percent error of approximation of $M_{2}(t)$ relative to the exact value. As it is seen from the table relative error is almost $0.698 \%$ when time is 20 units, but as the time increases relative error decreases dramatically. When time is 5000 units and relative error is almost zero. Further, relative error is much higher for $M_{1}(t)$ then $M_{2}(t)$ for smaller values of $t$.

Table 2. Moment Based Approximation Results for $M_{2}(t)$

\begin{tabular}{|c|c|c|c|}
\hline Time & Exact Values & $\begin{array}{c}\text { Approximation } \\
\text { Results }\end{array}$ & Rel-Err \\
\hline 20 & 0.019853674 & 0.0199923 & $0.698296 \%$ \\
\hline 50 & 0.049374055 & 0.0494041 & $0.060800 \%$ \\
\hline 100 & 0.098421339 & 0.0984237 & $0.002381 \%$ \\
\hline 250 & 0.245482506 & 0.2454825 & $0.000002 \%$ \\
\hline 500 & 0.490580546 & 0.4905806 & $0.000001 \%$ \\
\hline 1000 & 0.980776624 & 0.9807766 & $0.000000 \%$ \\
\hline 2000 & 1.961168781 & 1.9611688 & $0.000001 \%$ \\
\hline 5000 & 4.902345252 & 4.9023453 & $0.000001 \%$ \\
\hline
\end{tabular}

Table 3 shows the percent error of approximation of $A(t)$ relative to the exact $A(t)$. Same conclusion can be made for availability also.

Table 3. Moment Based Approximation Results for $A(t)$

\begin{tabular}{|c|c|c|c|}
\hline Time & Exact Value & $\begin{array}{c}\text { Approximation } \\
\text { Results }\end{array}$ & Rel-Err \\
\hline 20 & 0.987462646 & 0.9803920 & $-0.716042 \%$ \\
\hline 50 & 0.98192317 & 0.9803920 & $-0.155936 \%$ \\
\hline 100 & 0.980511701 & 0.9803920 & $-0.012208 \%$ \\
\hline 250 & 0.980392214 & 0.9803920 & $-0.000022 \%$ \\
\hline 500 & 0.980392157 & 0.9803920 & $-0.000016 \%$ \\
\hline 1000 & 0.980392157 & 0.9803920 & $-0.000016 \%$ \\
\hline 2000 & 0.980392157 & 0.9803920 & $-0.000016 \%$ \\
\hline 5000 & 0.980392157 & 0.9803920 & $-0.000016 \%$ \\
\hline
\end{tabular}

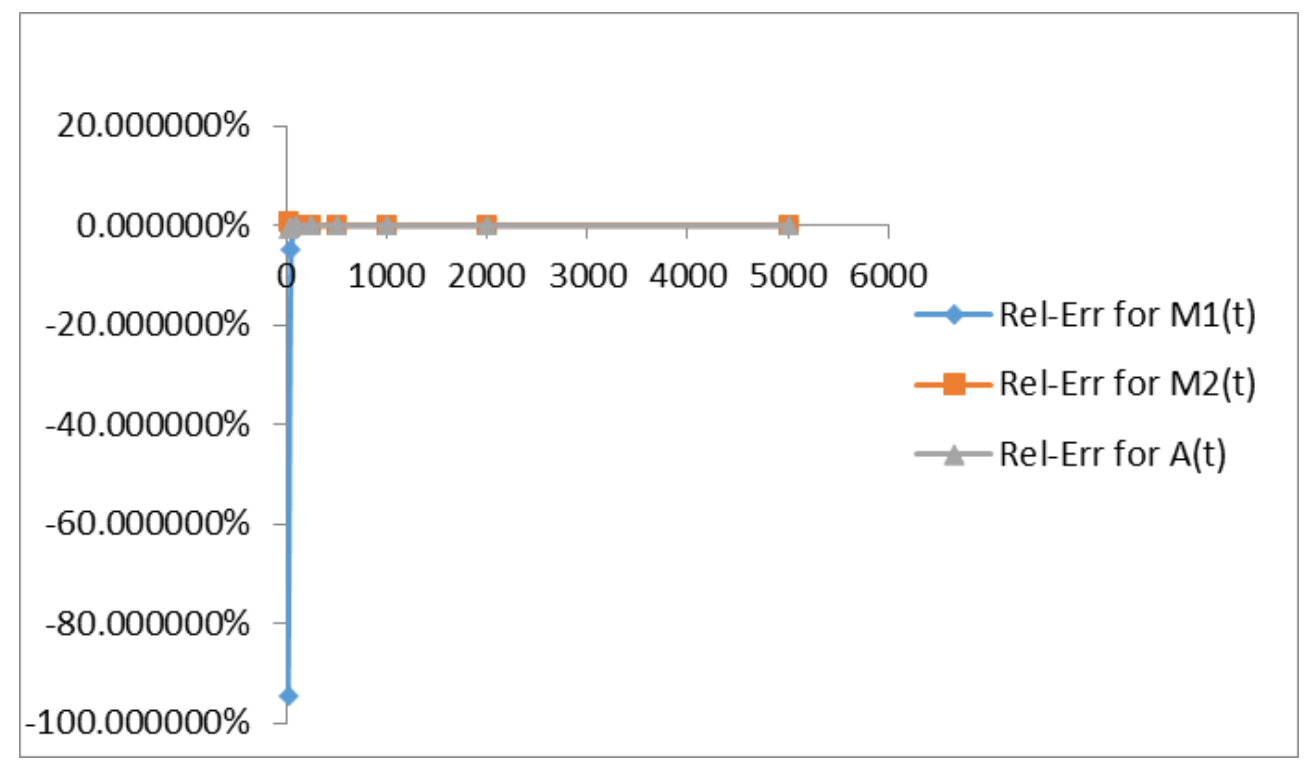

Figure 1. Relative Error versus Time Graph for $M_{1}(t), M_{2}(t)$ and $A(t)$ 
Figure 1 is the graphical representation of Table 1,2 and 3. It also shows that the approximation method works well for large values of $t$.

In this article, we explored the renewal functions for non-negligible repair for the most common reliability underlying distributions using the first four raw moments of the failure and repair distributions when the convolution of $f(t)$ and $r(t)$ is intractable. We conclude that the method produces very accurate results for especially large values of time $t$.

\section{Abbreviations}

MTTR, Mean Time to Repair; TTR, Time to Restore, or repair; pdf, probability density function; MTBF, Mean Time Between Failure.

\section{REFERENCES}

[1] E. A. Elsayed, Reliability Engineering, John Wiley \& Sons, Hoboken, NJ, USA, $2^{\text {nd }}$ edition, 2012.

[2] H. Parsa and M. Jin, "An Improved Approximation for the Renewal Function and Its Integral with an Application in Two Echelon Inventory Management," International Journal of Production Economics, 2013.

[3] S. Çetinkaya, E. Tekin, and C.-Y. Lee, "A stochastic model for joint inventory and outbound shipment decisions," IIE Transactions, vol. 40, no. 3, pp. 324-340, 2008.

[4] S. Karlin and A. J. Fabens, "Generalized renewal functions and stationary inventory models," Journal of Mathematical Analysis and Applications, vol. 5, no. 3, pp. 461-487, Dec. 1962.

[5] G. Yang, "A Renewal-Process Approach to Continuous Sampling Plans," Technometrics, vol. 25, pp. 59-67, 1983.

[6] G. Yang, "Application of Renewal Theory to Continuous Sampling Plans," Naval Research Logistics Quarterly, vol. 32, pp. 45-51, 1985.

[7] T. L. Lai and D. Siegmund, "A Nonlinear Renewal Theory with Applications to Sequential Analysis I," Ann. Statist., vol. 5, no. 5, pp. 946-954, Sep. 1977.

[8] T. L. Lai and D. Siegmund, "A Nonlinear Renewal Theory with Applications to Sequential Analysis II," Ann. Statist., vol. 7, no. 1, pp. 60-76, Jan. 1979.

[9] W. Blischke and D. N. P. Murthy, Warranty Cost Analysis, 1.st ed. CRC Press, 1994.

[10] M. L. Spearman, "A Simple Approximation for IFR Weibull Renewal Functions," Microelectronics Reliability, vol. 29, no. 1, pp. 73-80, 1989.

[11] S. Maghsoodloo and D. Helvaci, Renewal and Renewal Intensity Functions with Minimal Repair, Journal of Quality and Reliability Engineering (2014), Article ID 857437, 10 pp.

[12] U. N. Bhat, Elements of Applied Stochastic Processes, 2nd ed. John Wiley \& Sons Inc, 1984.

[13]C. E. Ebeling, An Introduction to Reliability and Maintainability Engineering, 2nd ed. Long Grove, Ill.: Waveland Press, 2010.

[14] K. S. Trivedi, Probability and Statistics with Reliability, Queuing and Computer Science Applications. New York, etc.: Prentice Hall, 1982.

[15] J. Sarkar and G. Chaudhuri, "Availability of a system with gamma life and exponential repair time under a perfect repair policy," Statistics \&amp; Probability Letters, vol. 43, no. 2, pp. 189-196, 1999.

[16]E. A. Elsayed, Reliability Engineering, Har/Dsk. Prentice Hall, 1996.

[17] M. M. . Ananda and J. Gamage, "On steady state availability of a system with lognormal repair time," Applied Mathematics and Computation, vol. 150, no. 2, pp. 409-416, Mar. 2004.

[18] P. Chandrasekhar and R. Natarajan, "Confidence limits for steady-state availability of systems with a mixture of exponential and gamma operating time and lognormal repair time," Microelectronics Reliability, vol. 36, no. 9, pp. 13031304, Sep. 1996.

[19] M. M. A. Ananda, "Confidence intervals for steady state availability of a system with exponential operating time and lognormal repair time," Applied Mathematics and Computation, vol. 137, no. 2-3, pp. 499-509, May 2003.

[20] B. Lindsay, R. Pilla, and P. Basak, "Moment-Based Approximations of Distributions Using Mixtures: Theory and Applications," Annals of the Institute of Statistical Mathematics, vol. 52, no. 2, pp. 215-230, 2000.

[21] N. S. Kambo, A. Rangan, K. T. Tolling, and B. Hadji, "Moments-Based Approximation to the Renewal Function," Communication in Statistics-Theory and Methods, vol. 41, pp. 851-868, Jan. 2012. 